\title{
Estado nutricional do arroz cultivado em diferentes épocas e adubações sob cobertura morta ${ }^{1}$
}

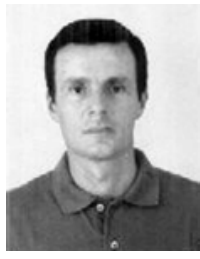

Maurício M. Parry², Janice G. de Carvalho ${ }^{3}$, Maria do S. A. Kato ${ }^{4}$ \& Konrad Vielhauer ${ }^{5}$

1 Parte da Tese de Doutorado do primeiro autor, apresentada UFLA.

2 UFLA, Bolsista do CNPq/SHIFT-Capoeira. Travessa Benjamim Constant, 877/1001.CEP 66.053-040, Belém, PA. Fone:(91) 224-0772. E-mail: mauricioparry@yahoo.com.br (Foto)

${ }^{3}$ Departamento de Ciência do Solos - UFLA

4 Embrapa Amazônia Oriental, CEP 66095-100, Belém, PA

5 Instituto de Agricultura Tropical da Universidade de Göttingen, Alemanha

Protocolo $143-1 / 10 / 2002$ - Aprovado em 2/6/2004

\begin{abstract}
Resumo: Com o objetivo de se avaliar o efeito de épocas de plantio e da adubação sobre o estado nutricional do arroz (Oryza sativa L. variedade "Maravilha") no final do ciclo, conduziu-se um experimento no município de Igarapé-Açu, Pará, num Latossolo Amarelo coeso típico. Testaramse quatro épocas de plantio e duas adubações, com delineamento experimental em blocos ao acaso, com parcelas subdivididas. A avaliação do estado nutricional foi feita na palhada e nos grãos. As maiores concentrações de $\mathrm{N}, \mathrm{P}, \mathrm{Ca}, \mathrm{B}$ e $\mathrm{Cu}$, foram observadas nos grãos e as maiores concentrações de $\mathrm{K}, \mathrm{Mg}, \mathrm{S}, \mathrm{Fe}, \mathrm{Mn}$ e $\mathrm{Zn}$, na matéria seca das plantas. As concentrações dos nutrientes foram afetadas significativamente pelas épocas de plantio 1 e 2 , sem que este fato impedisse a observação de concentrações consideradas adequadas nas plantas e grãos. A adubação com mais $\mathrm{P}$ promoveu significativos aumentos nos teores de $\mathrm{Cu}$ e $\mathrm{Zn}$ na planta, e de $\mathrm{P}, \mathrm{K}, \mathrm{Ca}$ e $\mathrm{Zn}$ nos grãos. Ocorreu interação significativa entre as épocas de plantio e adubações, apenas para as concentrações de Cu na planta e de Ca e Zn nos grãos. No período de maior precipitação observaramse as maiores concentrações de $\mathrm{P}$ e micronutrientes nas plantas.
\end{abstract}

Palavras-chave: nutrição de plantas, fertilidade do solo, Latossolo Amarelo, Amazônia Oriental

\section{Nutritional state of rice cultivation at different planting times and fertilization under mulching}

\begin{abstract}
To evaluate the effect of planting time and fertilization on the nutritional state of rice (Oryza sativa L. var. "Maravilha") at harvest stage, an experiment was carried out at the Igarapé$\mathrm{Accu}$, in the State of Pará in a typical Argissol (cohesive Yellow Latosol). Four times of planting and two fertilization rates were tested in a completely randomized block design with split-plot arrangement. The evaluation of the nutritional stage was done in mature plants and grains. The highest concentrations of $\mathrm{N}, \mathrm{P}, \mathrm{Ca}, \mathrm{B}$ and $\mathrm{Cu}$ were observed in the rice grains and the highest concentrations of $\mathrm{K}, \mathrm{Mg}, \mathrm{S}, \mathrm{Fe}, \mathrm{Mn}$ and $\mathrm{Zn}$ were found in the plants. The nutrient concentrations were affected significantly by the time of plantation 1 and 2, however, this fact did not prevent the presence of adequate contents of majority of nutrients in straw and grain. The fertilization with additional dose of $P$ increased significantly only the concentrations of $\mathrm{Cu}$ and $\mathrm{Zn}$ in the plant and of $\mathrm{P}, \mathrm{K}, \mathrm{Ca}$ and $\mathrm{Zn}$ in the grains. A significant interaction was observed between the time of planting and the fertilization for $\mathrm{Cu}$ content in the straw and of $\mathrm{Ca}$ and $\mathrm{Zn}$ contents in the grains. In the rainy season higher concentrations of $\mathrm{P}$ and micronutrients were observed in the plants.
\end{abstract}

Key words: plant nutrition, soil fertility, Yellow Latossol (Oxisol), Eastern Amazon

\section{INTRODUÇÃO}

Em regiões onde a agricultura tradicionalmente praticada é a de cultivo de subsistência e o arroz, o milho, a mandioca e o feijão caupi, são a base alimentar dessas populações, a disponibilidade de elementos minerais às plantas é, sem dúvida, o fator primordial ao qual essas culturas de ciclo curto respondem com crescimento, desenvolvimento e produções permitindo, desta forma, que as famílias proprietárias de pequenos lotes agrícolas e de domínio restritamente familiar, 
como na grande maioria da Amazônia Oriental, se mantenham no campo.

A quantidade e o estado em que os elementos minerais se encontram no solo, definem as maneiras de suprir as necessidades nutricionais e metabólicas, pela absorção dos elementos químicos necessários às plantas. Entre as limitações de natureza química, Cravo \& Smyth (1991) consideram o P como elemento mais limitante ao desenvolvimento das culturas, embora deficiente em $90 \%$ dos solos da região, seguido pelo $\mathrm{K}$ e N. As formas com que o conjunto de processos e reações afeta o conjunto dos nutrientes no sistema solo-planta, determinarão a manutenção da vida e o crescimento dos constituintes de seu metabolismo.

O manejo de área tradicional nessas regiões, denominado agricultura migratória, utilizado há tempos pelas tribos indígenas, é caracterizado pelo sistema de derruba e queima de pequenas áreas de floresta ou vegetação secundária, geralmente entre 0,33 e 2,0 ha ano ${ }^{-1}$ (Sampaio, 1998). A vegetação possui grande capacidade de regeneração, repondo a biomassa anterior porém, com o tempo de pousio reduzido, a reposição dos nutrientes se faz de maneira lenta e incompleta, por haver a quebra do sistema solo-planta, provocando a depressão das produções.

A cultura do arroz é introduzida no campo com o início do período chuvoso, que se estende de janeiro a maio e como alternativa para cultivos nos trópicos úmidos; Ewel et al. (1991) apontam a adoção de práticas culturais que simulem os ciclos dos nutrientes da vegetação nativa. Sistemas de cultivo que protejam o solo pela adoção de cobertura viva ou morta, como também de maiores aportes de nutrientes sem que haja o comprometimento da regeneração da vegetação secundária (o que normalmente ocorre com a queimada), para que o período de pousio possa restabelecer a fertilidade do solo em menor espaço de tempo que o tradicional requer, demonstrando um dos possíveis caminhos para a sustentabilidade da agricultura na Amazônia.

Entre diferentes tipos de preparo de área, dentre eles os métodos em que se empregavam a queima e a não queima, Ghuman \& Lal (1991) verificaram que a prática de cultivo sobre a vegetação somente derrubada, melhorou significativamente todas as propriedades químicas avaliadas $(\mathrm{pH}, \mathrm{C}$ orgânico, $\mathrm{N}$ total, $\mathrm{Ca}, \mathrm{Mg}$ e $\mathrm{K}$ ) ficando estes sempre em cima de todos os demais tratamentos, durante os quatro anos de estudo, numa região tropical úmida da Nigéria. Ao final dos estudos, os mesmos autores recomendaram a prática de derruba e não queima como sendo a ideal para regiões tropicais úmidas. Entretanto, Roder et al. (1998) verificaram que esta prática apresenta alguns inconvenientes, como a diminuição em $43 \%$ da produção de arroz em Laos (África), principalmente quando o material da cobertura morta é originário de espécies leguminosas cultivadas na área. Decréscimo semelhante de produção (47-80\%), só o verificado por Kato et al. (1999) em sistema de derruba e queima. Em sistemas livres de fogo, o acréscimo na produção foi de $47 \%$ na cultura do arroz e de $27 \%$ na de feijão (Kato et al., 1999).

Na cultura do arroz, as respostas à adubação potássica não têm sido verificadas com tanta freqüência como para nitrogênio e fósforo (Fornasieri Filho \& Fornasieri, 1993). A deficiência de potássio geralmente está associada à toxidez de ferro (Lopes, 1996); já Assis (1997) comenta que as deficiências de N e P provocam decréscimo no perfilhamento e a matéria seca da parte aérea é afetada pela ausência de N, P e K. No caso do enxofre, por ser aplicado como nutriente secundário na forma de sulfato de amônio e super simples, pouca atenção tem sido dada à demanda de $\mathrm{S}$ pelo arroz mas, com a tendência de se substituir essas formas de nutrientes por formulações mais concentradas, a deficiência de $\mathrm{S}$ tende a aumentar (Mesquita,1993).

A composição mineral dos grãos é importante não só para a alimentação mas, também, para a germinação das sementes. Um aspecto importante é a remobilização de nutrientes para a formação de raízes e parte aérea, enquanto a absorção de nutrientes minerais do solo é inadequada. O N é um dos nutrientes de maior influência sobre a produção e a qualidade protéica dos grãos; entretanto, existem poucas informações sobre o efeito da fertilização nitrogenada na acumulação e remobilização de nutrientes minerais (Marschner, 1995).

Para as semeaduras em períodos com menor precipitação, recomendam-se variedades precoces. Desta forma, Costa \& Campos (1993) em pesquisas realizadas no Acre, conseguiram boas produções de grãos fora da estação ideal (a partir de outubro) plantando nos meses de março e abril, proporcionando duas safras por ano agrícola.

Objetivou-se, com este trabalho, avaliar o estado nutricional da cultura do arroz (palha e grãos), ao final do ciclo, tendo-se as concentrações de nutrientes determinadas como forma de comparação com valores considerados adequados em plantas sadias também na colheita.

\section{MATERIAL E MÉTODOS}

O experimento foi instalado e conduzido em propriedade de pequeno agricultor da comunidade Nossa Senhora de Belém, localizado no Município de Igarapé-Açu, no Nordeste paraense, nas coordenadas $01^{\circ} 11^{\prime} \mathrm{S}$ e $47^{\circ} 35^{\prime} \mathrm{W}$ (Bastos et al., 1995) distante $140 \mathrm{~km}$ de Belém.

O clima da região é do tipo Ami, na classificação de Köppen, quente e úmido, tipicamente equatorial, com temperaturas médias sempre superiores a $18{ }^{\circ} \mathrm{C}$. As médias anuais são superiores a $27{ }^{\circ} \mathrm{C}$. As precipitações mensais ultrapassam $60 \mathrm{~mm}$, com exceção do período de verão (setembro - novembro) quando as precipitações são inferiores, sem caracterizar uma estação seca definida. A precipitação média anual é de 2.400 $\mathrm{mm}$ (Figura 1).

O solo da área experimental é um Latossolo Amarelo coeso típico (Lax) com baixos teores de matéria orgânica, fósforo assimilável, bases trocáveis e CTC, (Tabela 1). A vegetação que o recobria era uma capoeira de sete anos de idade.

Utilizou-se o delineamento de blocos ao acaso, com quatro tratamentos (épocas de plantio), duas adubações diferentes por parcela, formando as subparcelas, com quatro repetições cada uma. As parcelas mediam 23,0 × 23,0 m, separadas umas das outras por passarelas de $1,5 \mathrm{~m}$ de largura, enquanto as subparcelas possuíam $11,5 \times 23,0 \mathrm{~m}$, sendo a área colhida nas subparcelas foi de $9,0 \mathrm{~m}^{2}$. 


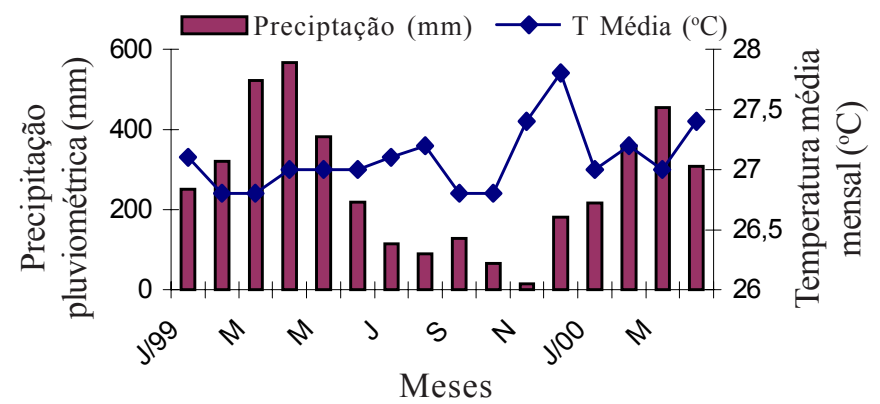

Figura 1. Dados agrometeorológicos do município de IgarapéAçu, Pará.

Tabela 1. Atributos químicos e físicos do Latossolo Amarelo coeso, típico da área experimental no Município de IgarapéAçu, Pará.

\begin{tabular}{ccrrrr}
\hline \multirow{2}{*}{ Atributo* } & \multirow{2}{*}{ Unidade } & \multicolumn{4}{c}{ Profundidades $(\mathrm{cm})$} \\
\cline { 3 - 6 } $\mathrm{pH}\left(\mathrm{H}_{2} \mathrm{O}\right)$ & & $0-10$ & $10-20$ & $20-30$ & $30-50$ \\
$\mathrm{P}$ & $\mathrm{mg} \mathrm{dm}^{-3}$ & 3,0 & 5,2 & 5,1 & 5,0 \\
$\mathrm{~K}$ & $\mathrm{mg} \mathrm{dm}^{-3}$ & 45,0 & 27,0 & 20,0 & 13,0 \\
$\mathrm{Ca}$ & $\mathrm{cmol}_{\mathrm{c}} \mathrm{dm}^{-3}$ & 2,0 & 1,0 & 0,8 & 0,6 \\
$\mathrm{Mg}$ & $\mathrm{cmol}_{\mathrm{c}} \mathrm{dm}^{-3}$ & 0,7 & 0,4 & 0,3 & 0,3 \\
$\mathrm{Al}$ & $\mathrm{cmol}_{\mathrm{c}} \mathrm{dm}^{-3}$ & 0,2 & 0,3 & 0,6 & 0,7 \\
$\mathrm{H}+\mathrm{Al}$ & $\mathrm{cmol}_{\mathrm{c}} \mathrm{dm}^{-3}$ & 3,5 & 3,2 & 3,0 & 3,1 \\
$\mathrm{~S} . \mathrm{B}$. & $\mathrm{cmol}_{\mathrm{c}} \mathrm{dm}^{-3}$ & 2,9 & 1,5 & 1,2 & 1,0 \\
$\mathrm{t}$ & $\mathrm{cmol}_{\mathrm{c}} \mathrm{dm}^{-3}$ & 3,3 & 2,1 & 1,6 & 1,5 \\
$\mathrm{~T}$ & $\mathrm{cmol}_{\mathrm{c}} \mathrm{dm}^{-3}$ & 6,4 & 4,7 & 4,2 & 4,1 \\
$\mathrm{~m}$ & $\%_{0}$ & 6,8 & 20,8 & 31,1 & 39,0 \\
$\mathrm{~V}$ & $\%_{0}$ & 45,3 & 31,9 & 28,6 & 24,4 \\
M.O. & $\mathrm{dag} \mathrm{kg}^{-1}$ & 3,1 & 1,9 & 1,2 & 0,9 \\
Areia grossa & $\mathrm{g} \mathrm{kg}^{-1}$ & 68,0 & 63,0 & 59,0 & 53,0 \\
Areia fina & $\mathrm{g} \mathrm{kg}^{-1}$ & 19,0 & 21,0 & 20,0 & 22,0 \\
Silte & $\mathrm{g} \mathrm{kg}^{-1}$ & 5,0 & 5,0 & 4,0 & 6,0 \\
Argila & $\mathrm{g} \mathrm{kg}^{-1}$ & 8,0 & 11,0 & 17,0 & 19,0 \\
Densidade & $\mathrm{kg} \mathrm{dm}^{-3}$ & 1,27 & 1,47 & 1,49 & 1,51 \\
\hline * Determinações realizadas segundo metodologia da EMBRAPA (1997) &
\end{tabular}

O preparo de área se deu com o corte e trituração da capoeira, utilizando-se uma ensilhadeira acoplada a um trator de rodas. A biomassa foi espalhada de maneira uniforme sobre o solo das parcelas, formando a cobertura morta, deixando-se fermentar e secar por aproximadamente 20 dias, quando da realização dos primeiros plantios. Os tratamentos foram: época de plantio 1 (tratamento 1) plantio de arroz em fevereiro de 1999; época de plantio 2 (tratamento 2) plantio em março de 1999; época de plantio 3 (tratamento 3) plantio em outubro de 1999; e época de plantio 4 (tratamento 4) plantio em novembro de 1999. Os tratamentos 1 e 2 foram plantios realizados no período de precipitações mais intensas e os tratamentos 3 e 4 , no período de menor precipitação, sem prejuízo à cultura. Antes do plantio do arroz foram cultivados milho (Zea mays L.) e mandioca (Manihot esculenta Crantz) em todas as parcelas e nas parcelas dos tratamentos 3 e 4, também foi cultivado o caupi (Vigna unguiculata L. Walp.) sendo, portanto, passados 12 meses do preparo inicial das áreas nos tratamentos 1 e 2 e 1 ano e 5 meses nos tratamentos 3 e 4 . Não foi feita a destoca das parcelas, com vistas à regeneração natural da vegetação.

Usou-se adubo químico na forma de duas adubações para a cultura do arroz: adubação $1,50 \mathrm{~kg} \mathrm{ha}^{-1} \mathrm{de} \mathrm{N}, 25 \mathrm{~kg} \mathrm{ha}^{-1}$ de P e $25 \mathrm{~kg} \mathrm{ha}^{-1}$ de K; e adubação $2,50 \mathrm{~kg} \mathrm{ha}^{-1}$ de N, $50 \mathrm{~kg} \mathrm{ha}^{-1}$ de P e $25 \mathrm{~kg} \mathrm{ha}^{-1}$ de $\mathrm{K}$; tendo-se como fontes de $\mathrm{N}$ a uréia, de $\mathrm{P}$ o superfosfato triplo e de $\mathrm{K}$ o cloreto de potássio. Essas foram as adubações mínimas para a cultura do arroz, recomendadas pela EMBRAPA Amazônia Oriental.

Para efeito de avaliação do estado nutricional do arroz, foi coletada a parte aérea da planta ao final do ciclo possibilitando, desta forma, comparar-se as concentrações destas com a de plantas sadias também ao final do ciclo e avaliar as quantidades de nutrientes exportadas com as colheitas. As plantas foram divididas em palhada e grãos com casca. As áreas foram amostradas dentro de cada subparcela, eliminando-se as bordas. Todas as amostras foram embaladas em sacos de papel, identificadas e secadas em estufa, com circulação de ar forçada a $65^{\circ} \mathrm{C}$, até atingirem peso constante. Os grãos de arroz ficaram, no final deste processo, com $13 \%$ de umidade. Após a secagem foram moídas, peneiradas e levadas para análise.

As análises foram realizadas pelos Laboratórios de Análise Foliar do Departamento de Ciência do Solo da Universidade Federal de Lavras, MG, e da EMBRAPA Amazônia Oriental Belém, PA, conforme metodologia preconizada por Malavolta et al. (1997). Determinaram-se os teores de macro e micro nutrientes na matéria seca da palha e dos grãos.

Os dados experimentais foram submetidos à análise de variância e usado o teste F para aferir o nível de significância. Os fatores analisados nas parcelas foram as épocas de plantio e, nas subparcelas, duas adubações. Para as análises em que houve significância, procedeu-se ao teste de médias entre os tratamentos, por intermédio do teste de Scott-Knott a nível de $5 \%$ de probabilidade, empregando-se o software Sisvar (Ferreira, 2000) sem transformar os dados.

\section{RESULTADOS E DISCUSSÃO}

\section{Estado nutricional da cultura do arroz}

Palha: Na Tabela 2 tem-se as significâncias resultantes da análise de variância. Como se observa, houve efeito significativo das épocas de plantio sobre as concentrações de todos os nutrientes (variáveis) avaliados e, também, efeito significativo das adubações sobre as concentrações de $\mathrm{Cu}$ e $\mathrm{Zn}$. A interação proporcionou efeito significativo sobre as concentrações de $\mathrm{Cu}$.

Observam-se diferenças significativas entre as concentrações de $\mathrm{N}$ nas épocas. As épocas mais tardias (março de 1999 e novembro de 2000) foram as que apresentaram as maiores concentrações, sendo a época 4 (novembro) superior a 2 (março) em 51\% (Tabela 2). Uma possível explicação para este aumento na concentração de $\mathrm{N}$ observado na época 4 , pode ser o favorecimento que a cultura do caupi pode ter proporcionado ao plantio, com a introdução no sistema de uma dose extra de N, por ter sido cultivado antes do arroz, proporcionando também o maior desenvolvimento, diluindo as concentrações. Este fato, entretanto, não explica a baixa concentração observada na época 3 , que também poderia ser beneficiada pelo mesmo motivo e não o foi. Os teores dos plantios 1, 2 e 3 foram considerados semelhantes e inferiores, estatisticamente, ao teor médio observado em plantas do plantio 4. 
Tabela 2. Concentração de nutrientes na matéria seca de plantas de arroz cultivadas em diferentes épocas sob cobertura morta e duas adubações*

\begin{tabular}{|c|c|c|c|c|c|c|c|c|c|c|c|}
\hline \multirow{2}{*}{$\begin{array}{c}\text { Épocas de } \\
\text { Plantio }\end{array}$} & $\mathrm{N}$ & $P$ & $\mathrm{~K}$ & $\mathrm{Ca}$ & $\mathrm{Mg}$ & S & B & $\mathrm{Cu}$ & $\mathrm{Fe}$ & $\mathrm{Mn}$ & $\mathrm{Zn}$ \\
\hline & \multicolumn{6}{|c|}{$\mathrm{g} \mathrm{kg}^{-1}$} & \multicolumn{5}{|c|}{$\mathrm{mg} \mathrm{kg}^{-1}$} \\
\hline 1 & $8,9 \mathrm{ab}$ & $1,0 \mathrm{~b}$ & $16,8 \mathrm{a}$ & $3,6 \mathrm{~b}$ & $2,1 \mathrm{a}$ & $1,3 \mathrm{~b}$ & $15,4 \mathrm{a}$ & $13,6 \mathrm{a}$ & $151,1 \mathrm{a}$ & $722,5 \mathrm{a}$ & $82,4 \mathrm{a}$ \\
\hline 3 & $7,8 \mathrm{~b}$ & $0,8 \mathrm{~b}$ & $6,5 \mathrm{~b}$ & $4,6 \mathrm{a}$ & $2,0 \mathrm{a}$ & $6,3 \mathrm{a}$ & $6,9 \mathrm{~b}$ & $8,1 \mathrm{ab}$ & $130,1 \mathrm{~b}$ & $33,6 \mathrm{~b}$ & $25,6 \mathrm{c}$ \\
\hline 4 & $16,3 \mathrm{a}$ & $3,1 \mathrm{a}$ & $2,5 \mathrm{c}$ & $4,3 \mathrm{ab}$ & $1,5 \mathrm{~b}$ & $1,5 \mathrm{~b}$ & $3,7 \mathrm{~b}$ & $5,7 \mathrm{~b}$ & $156,1 \mathrm{a}$ & $33,1 \mathrm{~b}$ & $30,3 \mathrm{c}$ \\
\hline \multicolumn{12}{|l|}{ Adubações } \\
\hline CV (\%) & 44,5 & 32,6 & 22,2 & 12,8 & 19,9 & 17,8 & 22,9 & 42,0 & 19,2 & 51,5 & 32,4 \\
\hline
\end{tabular}

As concentrações de $\mathrm{N}$ observadas indicaram somente $25 \%$ da considerada adequada (Malavolta et al., 1997) mas não houve sintomas visíveis de sua deficiência no campo. Resultados idênticos foram observados por Bezerra Neto et al. (2000) em solos salinos. Para as faixas consideradas adequadas por Reuter \& Robinson (1997), Fageria et al. (1995) e Pauletti (1998) estas também se encontravam abaixo, porém, apenas 30 e $50 \%$, respectivamente.

Não houve diferenças entre as adubações praticadas nem efeito da interação entre as épocas de plantio e as adubações, não só para o $\mathrm{N}$ mas, também, em relação aos demais macronutrientes.

A época 4 apresentou, para o $\mathrm{P}$ e o $\mathrm{N}$, a maior média de concentração deste nutriente nas plantas de arroz, na época da colheita, cujo resultado foi três vezes superior às demais concentrações em média. As épocas de plantio 1, 2 e 3 não diferiram pelo teste de médias. As concentrações foram consideradas abaixo da concentração adequada (Malavolta et al., 1997) em alguns casos e, dentro dos limites mínimos, considerados adequados em outros (Fageria et al., 1984; Fageria et al., 1995; Reuter \& Robinson, 1997). As concentrações de P nas plantas na época da colheita foram semelhantes às observadas por Galrão et al. (1978) em Latossolo Vermelho do Distrito Federal e por Bastos (1999) em solos de várzea de Minas Gerais.

Para o K, as maiores concentrações foram constatadas nas épocas de plantio de arroz no campo, realizado no início do ano agrícola de 1999 (estação com maior precipitação) épocas 1 e 2, sendo também consideradas semelhantes e significativamente superiores às épocas 3 e 4 . Como nesse tempo a cobertura morta já se havia decomposto quase por completo (observações de campo), pode ter sido responsável, em parte, pelo maior fornecimento desse nutriente para a cultura, nas citadas épocas.

As concentrações de $\mathrm{K}$ observadas nos dados contidos na Tabela 2 estavam abaixo das recomendadas como adequadas, por Malavolta et al. (1997) e Pauletti (1998), mas se enquadraram na faixa recomendada por Reuter \& Robinson (1997). Nos tratamentos 1 e 2, as concentrações de $\mathrm{K}$ foram consideradas adequadas pela faixa proposta por Fageria et al. (1995).

As diferenças apresentadas pelas concentrações de $\mathrm{Ca}$ e $\mathrm{Mg}$ foram bem menores mas igualmente diferentes pelo teste de médias. A menor variação ocorreu entre as concentrações de $\mathrm{Mg}$. As épocas 1, 2 e 3 não diferiram e foram significativamente superiores à concentração da época 4.
Comportamento semelhante tiveram as concentrações de $\mathrm{S}$, em que apenas a da época 3 foi diferente e superior às demais. As concentrações de $\mathrm{Ca}, \mathrm{Mg}$ e $\mathrm{S}$ para plantas de arroz em seu estádio final de desenvolvimento, foram consideradas adequadas (Fageria et al., 1984; Fageria et al., 1995; Reuter \& Robinson, 1997; Malavolta et al., 1997; Pauletti, 1998). Resultados superiores para as concentrações de $\mathrm{Ca}$ e semelhantes para as de $\mathrm{Mg}$ foram observados por Bezerra Neto et al. (2000); já Galrão et al. (1978) constataram concentrações maiores de $\mathrm{Ca}$ e $\mathrm{Mg}$ no tecido da planta, quando estudavam o efeito da omissão de micronutrientes num Latossolo Vermelho do Distrito Federal.

Silva et al. (1998) observaram concentrações semelhantes de $\mathrm{N}$ e $\mathrm{Ca}$, em plantas jovens cultivadas em solos de várzea de Roraima, sob o efeito de todos os tratamentos com omissão individual de nutrientes. Esses mesmos autores relataram valores mais elevados para as concentrações de $\mathrm{P}, \mathrm{K}$ e $\mathrm{Mg}$.

Geralmente, as maiores concentrações de micronutrientes foram observadas nas épocas de plantio 1 e 2 . Os plantios dessas épocas foram realizados no início de 1999 e os resultados foram idênticos a alguns obtidos por macronutrientes, cuja causa pode ser a mesma, a maior liberação de nutrientes pela decomposição e mineralização da cobertura morta, pois é a matéria orgânica a maior fornecedora de micronutrientes para o solo (Malavolta, 1980).

Foram significativamente superiores as diferenças observadas entre as concentrações de B das épocas 1 e 2, para as das épocas 3 e 4 . Assim, também o foram para o nutriente $\mathrm{Fe}$ entre as épocas 1 e 4 para a 2 e a 3 , e para as concentrações de Mn entre as épocas 1 e 2 para as épocas 3 e 4.

As adubações só influenciaram significativamente as concentrações de $\mathrm{Cu}$ e $\mathrm{Zn}$, observando-se a maior concentração sob a adubação 2 e a 1, para os dois nutrientes, respectivamente. Só se constatou efeito significativo da interação entre épocas de plantio e adubação, sobre as concentrações de $\mathrm{Cu}$. As épocas de plantio influenciaram significativamente as concentrações de $\mathrm{Zn}$, sendo maiores nas épocas 1 e 2, o que também ocorreu com o B.

As concentrações de B foram consideradas adequadas pela faixa proposta por Reuter \& Robinson (1997) e baixas, quando comparadas com as faixas propostas por Fageria et al. (1995), Malavolta et al. (1997) e por Pauletti (1998). As de Cu foram consideradas adequadas quando comparadas com a faixa de Fageria et al. (1995) e baixas pela de Malavolta et al. (1997). As 
concentrações de $\mathrm{Fe}$ e de $\mathrm{Zn}$ foram consideradas adequadas (Fageria et al., 1995; Malavolta et al., 1997; Reuter \& Robinson, 1997; Pauletti, 1998).

Conforme observado na Tabela 2, com o efeito significativo da interação (épocas de plantio x adubações) sobre a variável $\mathrm{Cu}$, sentiu-se a necessidade de se desdobrar seus resultados, que são apresentados na Tabela 3 .

Tabela 3. Valores médios* das concentrações de cobre na matéria seca de plantas de arroz cultivadas em diferentes épocas sob cobertura morta e duas adubações

\begin{tabular}{ccc}
\hline \multirow{2}{*}{ Épocas de Plantio } & \multicolumn{2}{c}{ Concentração $\mathrm{Cu}\left(\mathrm{mg} \mathrm{kg}^{-1}\right)$} \\
\cline { 2 - 3 } & $\mathrm{NPK}$ & $\mathrm{NPK}+\mathrm{P}$ \\
\hline 1 & $6,9 \mathrm{bB}$ & $20,3 \mathrm{aA}$ \\
3 & $11,0 \mathrm{aA}$ & $13,4 \mathrm{bA}$ \\
4 & $8,4 \mathrm{aA}$ & $7,7 \mathrm{bA}$ \\
Média & $5,2 \mathrm{bA}$ & $6,2 \mathrm{bA}$ \\
\hline
\end{tabular}

* Médias seguidas pela mesma letra minúscula nas colunas e maiúscula nas linhas, não diferem pelo teste de Scott-Knott, a $\mathrm{p}<0,05$

No caso específico do Mn, dois foram os comportamentos distintos para as concentrações observadas, sendo um para as das épocas 1 e 2 e outro completamente diferente para as épocas 3 e 4 . As concentrações das épocas 1 e 2 foram consideradas adequadas (Reuter \& Robinson, 1997; Pauletti, 1998) para plantas de arroz no estádio final da cultura, ou seja, já no período da colheita. Para as concentrações observadas nas épocas 3 e 4 e apesar de se tratar de plantas também no estádio final da cultura, foram consideradas concentrações de plantas jovens, em estádio de início de floração ou até antes (Fageria et al., 1995; Malavolta et al., 1997; Reuter \& Robinson, 1997). Este fato pode, em alguns casos, ser explicado, devido à grande amplitude das faixas propostas pelos autores.

Estudando a nutrição de variedades de arroz em diferentes solos de várzea, Bastos (1999) observou resultados semelhantes para as concentrações de $\mathrm{Cu}$, inferiores para $\mathrm{B}$ mas superiores para as concentrações de Fe, Mn e Zn. O efeito da maior concentração de matéria orgânica nos solos de várzea pode ser a resposta para as maiores diferenças, sobretudo nos casos das concentrações de Fe e Mn entre esses estudos.

Galrão et al. (1978) observaram valores mais baixos nas concentrações de $\mathrm{Cu}, \mathrm{Mn}$ e $\mathrm{Zn}$ nas plantas, ao fornecerem e omitir individualmente esses nutrientes, que as concentrações aqui observadas.

\section{Grãos}

Ao contrário do que foi verificado com as plantas, em que as maiores concentrações dos nutrientes foram observadas nos plantios do início de 1999 (épocas de plantio 1 e 2), as maiores concentrações dos macronutrientes nos grãos ocorreram dos plantios realizados no final de 1999 e no início de 2000 (tratamentos 3 e 4).

Constatou-se diferença significativa entre as concentrações de $\mathrm{N}$ nas épocas de plantio. O plantio 3 foi estatisticamente superior aos demais, que foram considerados semelhantes entre si, enquanto as adubações não diferiram.

Não ocorreu diferença entre as concentrações de $\mathrm{P}$ dos grãos nos plantios mas, sim, diferença significativa provocada pelas adubações, sendo que a adubação 2 proporcionou maiores concentrações de $\mathrm{P}$ nos grãos de arroz. Foi nos grãos, também, que se observaram as maiores concentrações de N, P e Ca, em comparação com a planta.

Observaram-se diferenças significativas entre as concentrações do $\mathrm{K}$ nos plantios. Os plantios das épocas 3 e 4 foram considerados semelhantes, porém inferiores ao da época 1 e superiores ao da época 2. Segundo avaliações de Reuter \& Robinson (1997) as concentrações de K observadas nos plantios 1, 3 e 4 se encontram bem acima das concentrações de $\mathrm{K}$ consideradas deficientes ou críticas $\left(4,0 \mathrm{~g} \mathrm{~kg}^{-1}\right)$; possivelmente, devem estar dentro das faixas consideradas adequadas. Como se observa na Tabela 4, a concentração de K da época de plantio 2 se encontra, segundo esses autores, no limite considerado crítico sem, entretanto, ter sido observado sintoma de deficiência no campo.

As maiores concentrações de $\mathrm{Ca}, \mathrm{Mg}$ e $\mathrm{S}$ foram encontradas nos plantios 3 e 4, sendo esses considerados diferentes e superiores aos plantios 1 e 2. Para cada um dos três casos $(\mathrm{Ca}$, $\mathrm{Mg}$ e S) os plantios das épocas 1 e 2 foram considerados iguais. Houve, ainda, diferenças significativas entre as concentrações de S nos tratamentos.

Segundo Reuter \& Robinson (1997) as concentrações de $\mathrm{Ca}$ apresentadas pelos grãos das épocas 1, 2 e 3 e de $\mathrm{S}$ na época de plantio 1, estariam demonstrando elevado grau de deficiência desses nutrientes nos plantios, fatos que não puderam ser observados no campo. As demais concentrações dos referidos nutrientes foram ditas adequadas pelas faixas apresentadas pelos autores.

A adubação 2, com maior quantidade de $\mathrm{P}$, promoveu as maiores concentrações de $\mathrm{K}$ e $\mathrm{Ca}$ nos grãos, em relação à adubação 1. Para o Mg e o S, não houve diferença entre elas.

Tabela 4. Concentração de nutrientes* na matéria seca de grãos de arroz cultivados em diferentes épocas sob cobertura morta e duas adubações

\begin{tabular}{|c|c|c|c|c|c|c|c|c|c|c|c|}
\hline \multirow{2}{*}{$\begin{array}{l}\text { Épocas de } \\
\text { Plantio }\end{array}$} & $\mathrm{N}$ & $\mathrm{P}$ & $\mathrm{K}$ & $\mathrm{Ca}$ & $\mathrm{Mg}$ & $\mathrm{S}$ & B & $\mathrm{Cu}$ & $\mathrm{Fe}$ & $\mathrm{Mn}$ & $\mathrm{Zn}$ \\
\hline & \multicolumn{6}{|c|}{$\mathrm{g} \mathrm{kg}^{-1}$} & \multicolumn{5}{|c|}{$\mathrm{mg} \mathrm{kg}^{-1}$} \\
\hline 1 & $12,4 \mathrm{~b}$ & $2,9 \mathrm{a}$ & $10,0 \mathrm{a}$ & $1,0 \mathrm{c}$ & $0,6 \mathrm{~b}$ & $0,8 \mathrm{~b}$ & $6,5 \mathrm{c}$ & $7,6 \mathrm{~b}$ & $45,6 \mathrm{~b}$ & $79,4 \mathrm{~b}$ & $27,5 \mathrm{a}$ \\
\hline 2 & $14,6 \mathrm{~b}$ & $2,5 \mathrm{a}$ & $4,0 \mathrm{c}$ & $1,3 \mathrm{c}$ & $0,7 \mathrm{~b}$ & $2,0 \mathrm{ab}$ & $6,7 \mathrm{c}$ & $9,0 \mathrm{~b}$ & $56,2 \mathrm{~b}$ & $92,1 \mathrm{ab}$ & $28,3 \mathrm{a}$ \\
\hline 3 & $38,3 \mathrm{a}$ & $2,4 \mathrm{a}$ & $7,1 \mathrm{~b}$ & $3,9 \mathrm{~b}$ & $2,6 \mathrm{a}$ & $2,9 a b$ & $41,0 \mathrm{a}$ & $28,7 \mathrm{a}$ & $118,2 \mathrm{a}$ & $107,4 \mathrm{a}$ & $33,8 \mathrm{a}$ \\
\hline 4 & $12,6 \mathrm{~b}$ & $2,3 \mathrm{a}$ & $6,1 \mathrm{~b}$ & $9,3 \mathrm{a}$ & $1,0 \mathrm{~b}$ & $3,2 \mathrm{a}$ & $24,0 \mathrm{~b}$ & $5,7 \mathrm{~b}$ & $67,7 \mathrm{ab}$ & $87,1 \mathrm{ab}$ & $23,2 \mathrm{~b}$ \\
\hline \multicolumn{12}{|l|}{ Adubações } \\
\hline NPK & $19,3 \mathrm{a}$ & $2,3 \mathrm{a}$ & $8,1 \mathrm{~b}$ & $5,8 \mathrm{a}$ & $1,5 \mathrm{a}$ & $2,5 \mathrm{a}$ & $19,6 \mathrm{a}$ & $13,0 \mathrm{a}$ & $77,8 \mathrm{a}$ & $85,8 \mathrm{a}$ & $28,4 \mathrm{a}$ \\
\hline $\mathrm{NPK}+\mathrm{P}$ & $19,6 \mathrm{a}$ & $2,7 \mathrm{a}$ & $9,3 \mathrm{a}$ & $6,6 \mathrm{a}$ & $1,4 \mathrm{a}$ & $1,9 \mathrm{a}$ & $19,5 \mathrm{a}$ & $12,5 \mathrm{a}$ & 66,0 a & $97,2 \mathrm{a}$ & $26,4 \mathrm{a}$ \\
\hline CV (\%) & 13,8 & 28,2 & 17,8 & 31,5 & 22,3 & 65,2 & 14,3 & 25,5 & 42,8 & 44,9 & 13,6 \\
\hline
\end{tabular}


Como o ocorrido para os macronutrientes, as maiores concentrações dos micronutrientes avaliados foram observadas na época de plantio 3 , sendo diferentes significativamente das demais. As maiores diferenças foram observadas entre as concentrações de B sendo o único micronutriente que apresentou concentração maior no grão que na planta.

A concentração de $\mathrm{Cu}$ da época de plantio 3 apresentou diferença significativa para as demais, que foram consideradas semelhantes. Fe e Mn apresentaram diferenças mais brandas entre as concentrações, mas a estatística também a considerou significativa; além disso, ocorreu diferença significativa entre as concentrações de Zn; entretanto, esta foi de apenas $28,7 \%$, em média, entre os plantios 1, 2 e 3 , que apresentaram as maiores concentrações em relação ao plantio 4.

Segundo Reuter \& Robinson (1997) as concentrações de Fe e $\mathrm{Zn}$ observadas nos grãos de arroz, em todas as épocas de plantio, foram consideradas adequadas.

O único efeito significativo da adubação e da interação entre as épocas de plantio e as adubações foi constatado sobre as concentrações de $\mathrm{Zn}$ e, em ambos os casos, os efeitos foram significativos.

Observaram-se, na maioria das vezes, as maiores concentrações de micronutrientes (B, $\mathrm{Cu}, \mathrm{Mn}$ e $\mathrm{Zn}$ ) nos plantios iniciados no período seco (épocas 3 e 4), com as colheitas no período de maior precipitação.

\section{Acúmulo de nutrientes na cultura do arroz}

Ocorreu efeito significativo das épocas de plantio sobre os acúmulos de todos os nutrientes, na biomassa aérea da cultura do arroz, ficando evidente a influência da maior ou menor precipitação sobre a absorção dos nutrientes. As adubações somente proporcionaram efeito significativo sobre a acumulação de P, K (Tabela 5), Ca (Tabela 6) e Cu (Tabela 7).

Geralmente, os maiores acúmulos de macronutrientes foram verificados nas plantas de arroz que receberam adubação $\mathrm{NPK}+\mathrm{P}$, sendo esta superior estatisticamente à adubação NPK (Tabelas 5 e 6). A época de plantio 3 (julho) apresentou os maiores acúmulos, com exceção para o $\mathrm{P}$, que foi acumulado em maior quantidade na época 4 (setembro) período com menor precipitação e as maiores exportações. As maiores exportações observadas nesta época foram em decorrência do maior volume de grãos produzido; entretanto a época de plantio 3 foi, em geral, superior às demais, tanto para o acúmulo de nutrientes como para a sua exportação.

Os resultados apresentados nas Tabelas 5 e 6 foram semelhantes aos observados por Malavolta et al. (1983) ao avaliarem o acúmulo total de macronutrientes por plantas de arroz de diversas cultivares, porém os resultados de acúmulo de macronutrientes nos grãos no presente estudo, com exceção para o K, foram superiores aos observados pelos autores.

As médias de macronutrientes acumulados na parte aérea da cultura de arroz, nas quatro épocas de plantio, foram semelhantes às observadas e recomendadas por Pauletti (1998) para proporcionar a produção de uma tonelada de grãos. O mesmo foi observado para os micronutrientes com os acúmulos apresentados nas Tabelas 7 e 8 superando, em alguns casos, os conteúdos demonstrados por Pauletti (1998). O fato que pode ser responsável por esses resultados é o bom estado nutricional da cultura nas épocas estudadas, pois as concentrações de todos os macro e micronutrientes nas plantas e grãos, com exceção do K, foram satisfatórias, de acordo com recomendações de Galrão et al. (1978), Fageria et al. (1984), Fageria et al. (1995), Malavolta et al. (1997), Reuter \& Robinson (1997), Pauletti (1998) e Bastos (1999).

A interação épocas de plantio $\mathrm{x}$ adubações proporcionou efeito significativo somente sobre o acúmulo de $\mathrm{Cu}$ na cultura do arroz.

Os maiores acúmulos de $\mathrm{Cu}$ e Fé, (Tabela 7), foram observados sob a época de plantio 3, os maiores de B e Mn o foram na época 2 e a época 1 promoveu os maiores acúmulos de Zn.

Observou-se efeito semelhante sobre os acúmulos dos nutrientes nos grãos, proporcionados pelas épocas de plantio, com exceção do Mn, além de efeito significativo das adubações sobre o acúmulo de todos os macronutrientes e de $\mathrm{B}$ nos grãos (Tabela 8). Efeito idêntico foi observado na interação épocas de plantio $x$ adubações, com exceção do $P$.

Tabela 5. Conteúdo de N, P e K na biomassa aérea total seca (A) e grãos (13\% de umidade) (B) da cultura de arroz, em função das épocas de plantio sob cobertura morta e duas adubações

\begin{tabular}{|c|c|c|c|c|c|c|c|c|c|}
\hline \multirow{3}{*}{ Época } & \multicolumn{8}{|c|}{ Acúmulo de macronutrientes $\left(\mathrm{kg} \mathrm{ha}^{-1}\right)$} & \multirow{3}{*}{ Média } \\
\hline & \multicolumn{2}{|c|}{$\mathrm{N}$} & \multirow{2}{*}{ Média } & \multicolumn{2}{|c|}{$\mathrm{P}$} & \multirow{2}{*}{ Média } & \multicolumn{2}{|c|}{$\mathrm{K}$} & \\
\hline & NPK & $\mathrm{NPK}+\mathrm{P}$ & & NPK & $\mathrm{NPK}+\mathrm{P}$ & & NPK & $\mathrm{NPK}+\mathrm{P}$ & \\
\hline \multicolumn{10}{|c|}{ A. Biomassa aérea total seca } \\
\hline 1 & 39,5 & 49,5 & $44,5 \mathrm{C}$ & 4,9 & 9,2 & $7,1 \mathrm{~B}$ & 48,2 & 49,1 & $48,7 \mathrm{~B}$ \\
\hline 2 & 58,7 & 62,5 & $60,6 \mathrm{~B}$ & 7,5 & 7,2 & $7,4 \mathrm{~B}$ & 52,7 & 59,9 & $56,3 \mathrm{~A}$ \\
\hline 3 & 95,4 & 130,8 & $113,1 \mathrm{~A}$ & 7,5 & 9,1 & $8,3 \mathrm{~B}$ & 58,6 & 66,8 & $62,7 \mathrm{~A}$ \\
\hline 4 & 70,5 & 79,0 & $74,7 \mathrm{~B}$ & 13,2 & 15,0 & $14,1 \mathrm{~A}$ & 22,2 & 32,2 & $27,2 \mathrm{C}$ \\
\hline Média & $66,0 \mathrm{a}$ & 80,4 a & - & $8,3 \mathrm{~b}$ & $10,1 \mathrm{a}$ & - & $45,4 \mathrm{~b}$ & $52,0 \mathrm{a}$ & - \\
\hline CV $(\%)$ & - & - & 25,6 & - & - & 20,1 & - & - & 17,1 \\
\hline \multicolumn{10}{|c|}{ B. Grãos ( $13 \%$ de umidade) } \\
\hline 1 & $16,0 \mathrm{bB}$ & $22,3 \mathrm{aB}$ & 19,1 & 3,7 & 5,2 & $4,5 \mathrm{~B}$ & $1,0 \mathrm{aC}$ & $2,1 \mathrm{aC}$ & 1,6 \\
\hline 2 & $21,0 \mathrm{aB}$ & $22,5 \mathrm{aB}$ & 21,7 & 3,4 & 4,2 & $3,8 \mathrm{~B}$ & $0,3 \mathrm{aC}$ & $0,8 \mathrm{aC}$ & 0,6 \\
\hline 3 & $74,7 \mathrm{bA}$ & $90,3 \mathrm{aA}$ & 82,5 & 4,3 & 6,0 & $5,2 \mathrm{~A}$ & $33,7 \mathrm{bA}$ & $40,1 \mathrm{aA}$ & 36,9 \\
\hline 4 & $14,8 \mathrm{aB}$ & $13,9 \mathrm{aC}$ & 14,4 & 2,1 & 2,9 & $2,5 \mathrm{C}$ & $16,7 \mathrm{bB}$ & $19,2 \mathrm{aB}$ & 17,9 \\
\hline Média & 31,6 & 37,2 & - & 3,4 & 4,6 & - & 12,9 & 15,6 & - \\
\hline CV (\%) & - & - & 11,5 & - & - & 17,8 & - & - & 10,6 \\
\hline
\end{tabular}


Tabela 6. Conteúdo* de Ca, Mg e S na biomassa aérea total seca (A) e grãos (13\% de umidade) (B) da cultura de arroz, em função das épocas de plantio sob cobertura morta e duas adubações

\begin{tabular}{|c|c|c|c|c|c|c|c|c|c|}
\hline \multirow{3}{*}{ Época } & \multicolumn{8}{|c|}{ Acúmulo de macronutrientes $\left(\mathrm{kg} \mathrm{ha}^{-1}\right)$} & \multirow{3}{*}{ Média } \\
\hline & \multicolumn{2}{|c|}{$\mathrm{Ca}$} & \multirow{2}{*}{ Média } & \multicolumn{2}{|c|}{$\mathrm{Mg}$} & \multirow{2}{*}{ Média } & \multicolumn{2}{|c|}{$\mathrm{S}$} & \\
\hline & NPK & $\mathrm{NPK}+\mathrm{P}$ & & NPK & $\mathrm{NPK}+\mathrm{P}$ & & NPK & $\mathrm{NPK}+\mathrm{P}$ & \\
\hline \multicolumn{10}{|c|}{ A. Biomassa aérea total seca } \\
\hline 1 & 9,9 & 13,8 & $11,9 \mathrm{D}$ & 7,0 & 8,1 & $7,6 \mathrm{C}$ & 4,7 & 5,2 & $4,9 \mathrm{~B}$ \\
\hline 2 & 19,0 & 20,2 & $19,6 \mathrm{C}$ & 9,2 & 8,9 & $9,0 \mathrm{~B}$ & 7,2 & 7,4 & $7,3 \mathrm{~B}$ \\
\hline 3 & 5,2 & 51,5 & $48,4 \mathrm{~A}$ & 12,8 & 13,8 & $13,3 \mathrm{~A}$ & 32,2 & 29,0 & $30,6 \mathrm{~A}$ \\
\hline 4 & 25,1 & 27,2 & $26,2 \mathrm{~B}$ & 6,7 & 6,5 & $6,6 \mathrm{C}$ & 9,1 & 8,7 & $8,9 \mathrm{~B}$ \\
\hline Média & $24,8 \mathrm{~b}$ & $28,2 \mathrm{a}$ & - & $8,9 \mathrm{a}$ & $9,3 \mathrm{a}$ & - & $13,3 \mathrm{a}$ & $12,6 \mathrm{a}$ & - \\
\hline CV $(\%)$ & - & - & 10,2 & - & - & 15,5 & - & - & 19,0 \\
\hline \multicolumn{10}{|l|}{ B. Grãos } \\
\hline 1 & $1,7 \mathrm{aC}$ & $2,0 \mathrm{aC}$ & 1,9 & $1,4 \mathrm{bB}$ & $1,6 \mathrm{aB}$ & 1,0 & $1,2 \mathrm{aC}$ & $1,5 \mathrm{aC}$ & 1,4 \\
\hline 2 & $24,4 \mathrm{bA}$ & 33,6 aA & 29,0 & $4,9 \mathrm{bA}$ & 5,9 aA & 5,4 & $5,5 \mathrm{bA}$ & $6,8 \mathrm{aA}$ & 2,2 \\
\hline 3 & $10,1 \mathrm{aB}$ & $10,5 \mathrm{aB}$ & 10,3 & $1,2 \mathrm{aC}$ & $1,0 \mathrm{bC}$ & 1,1 & $3,9 \mathrm{aB}$ & $3,2 \mathrm{bB}$ & 3,6 \\
\hline 4 & 9,4 & 11,9 & - & 2,2 & 2,5 & - & 2,9 & 3,2 & - \\
\hline Média & $1,3 \mathrm{aC}$ & $1,7 \mathrm{aC}$ & 1,5 & $1,3 \mathrm{bC}$ & $1,7 \mathrm{aB}$ & 1,5 & $1,0 \mathrm{aC}$ & $1,3 \mathrm{aC}$ & 1,2 \\
\hline CV $(\%)$ & - & - & 16,5 & - & - & 3,4 & - & - & 8,8 \\
\hline
\end{tabular}

Tabela 7. Conteúdo* de B, Cu e Fe na biomassa aérea seca (A) e grãos (13\% de umidade) (B) da cultura de arroz, em função das épocas de plantio sob cobertura morta e duas adubações

\begin{tabular}{|c|c|c|c|c|c|c|c|c|c|}
\hline \multicolumn{10}{|c|}{ Acúmulo de micronutrientes $\left(\mathrm{g} \mathrm{ha}^{-1}\right)$} \\
\hline \multirow[t]{2}{*}{ Época } & \multicolumn{2}{|c|}{$\mathrm{B}$} & \multirow[b]{2}{*}{ Média } & \multicolumn{2}{|c|}{$\mathrm{Cu}$} & \multirow[b]{2}{*}{ Média } & \multicolumn{2}{|c|}{$\mathrm{Fe}$} & \multirow[b]{2}{*}{ Média } \\
\hline & NPK & $\mathrm{NPK}+\mathrm{P}$ & & NPK & $\mathrm{NPK}+\mathrm{P}$ & & NPK & $\mathrm{NPK}+\mathrm{P}$ & \\
\hline \multicolumn{10}{|c|}{ A. Biomassa aérea total seca } \\
\hline 1 & 51,1 & 57,2 & $54,2 \mathrm{~B}$ & $30,8 \mathrm{bC}$ & $69,8 \mathrm{aB}$ & 50,3 & 488,7 & 587,3 & $538,0 \mathrm{C}$ \\
\hline 2 & 80,1 & 74,4 & $77,3 \mathrm{~A}$ & $52,5 \mathrm{aB}$ & $62,9 \mathrm{aB}$ & 57,7 & 482,7 & 561,8 & $522,2 \mathrm{C}$ \\
\hline 3 & 36,4 & 36,0 & $36,2 \mathrm{C}$ & $90,9 \mathrm{aA}$ & $96,2 \mathrm{aA}$ & 93,5 & 782,2 & 749,4 & $765,8 \mathrm{~A}$ \\
\hline CV $(\%)$ & - & - & 12,3 & - & - & 21,6 & - & - & 11,0 \\
\hline \multicolumn{10}{|l|}{ B. Grãos } \\
\hline 1 & $8,1 \mathrm{bA}$ & $12,1 \mathrm{aA}$ & 10,1 & 11,2 & 11,8 & $11,5 \mathrm{~B}$ & 62,4 & 77,8 & $70,1 \mathrm{~B}$ \\
\hline 2 & $8,8 \mathrm{bA}$ & $11,3 \mathrm{aA}$ & 10,1 & 12,5 & 14,3 & $13,4 \mathrm{~B}$ & 78,5 & 88,5 & $83,5 \mathrm{~B}$ \\
\hline 3 & $8,0 \mathrm{aA}$ & $9,6 \mathrm{aA}$ & 8,8 & 57,6 & 65,8 & $61,7 \mathrm{~A}$ & 263,6 & 238,4 & $251,0 \mathrm{~A}$ \\
\hline 4 & $3,0 \mathrm{aB}$ & $2,4 \mathrm{aB}$ & 2,7 & 6,2 & 6,4 & $6,3 \mathrm{~B}$ & 87,1 & 65,1 & $76,1 \mathrm{~B}$ \\
\hline
\end{tabular}

Tabela 8. Conteúdo* de Mn e Zn na biomassa aérea total seca (A) e grãos (13\% de umidade) (B) da cultura de arroz, em função das épocas de plantio e adubações

\begin{tabular}{|c|c|c|c|c|c|c|}
\hline \multirow{3}{*}{ Época } & \multicolumn{6}{|c|}{ Acúmulo de micronutrientes $\left(\mathrm{g} \mathrm{ha}^{-1}\right)$} \\
\hline & \multicolumn{2}{|c|}{$\mathrm{Mn}$} & \multirow{2}{*}{ Média } & \multicolumn{2}{|c|}{$\mathrm{Zn}$} & \multirow{2}{*}{ Média } \\
\hline & NPK & $\mathrm{NPK}+\mathrm{P}$ & & NPK & $\mathrm{NPK}+\mathrm{P}$ & \\
\hline \multicolumn{7}{|c|}{ A. Biomassa aérea total total seca } \\
\hline 1 & 2374,1 & 2000,7 & $2187,4 \mathrm{~A}$ & 338,6 & 218,7 & $278,7 \mathrm{~A}$ \\
\hline 2 & 2148,4 & 2398,6 & $2273,5 \mathrm{~A}$ & 246,1 & 217,7 & $231,9 \mathrm{~A}$ \\
\hline 3 & 1629,2 & 1534,4 & $1581,8 \mathrm{~B}$ & 175,6 & 177,5 & $176,6 . \mathrm{B}$ \\
\hline 4 & 1263,4 & 1439,5 & $1351,5 \mathrm{~B}$ & 142,6 & 145,2 & $143,9 \mathrm{~B}$ \\
\hline Média & $1853,8 \mathrm{a}$ & $1843,3 \mathrm{a}$ & - & $225,7 \mathrm{a}$ & $189,8 \mathrm{a}$ & - \\
\hline CV $(\%)$ & - & - & 21,4 & - & - & 28,7 \\
\hline \multicolumn{7}{|c|}{ B. Grãos (13\% de umidade) } \\
\hline 1 & 117,4 & 123,7 & 120,5 B & 37,7 & 46,7 & $42,2 \mathrm{~B}$ \\
\hline 2 & 129,3 & 144,6 & $137,0 \mathrm{~B}$ & 40,3 & 43,9 & $42,1 \mathrm{~B}$ \\
\hline 3 & 155,2 & 319,4 & $237,3 \mathrm{~A}$ & 71,6 & 73,0 & $72,3 \mathrm{~A}$ \\
\hline 4 & 99,9 & 95,5 & 97,2 B & 31,8 & 27,2 & $29,5 \mathrm{C}$ \\
\hline Média & $125,2 \mathrm{a}$ & $170,8 \mathrm{a}$ & - & $45,4 \mathrm{a}$ & $47,7 \mathrm{a}$ & - \\
\hline CV (\%) & - & - & 64,4 & - & - & 21,6 \\
\hline
\end{tabular}

* Médias seguidas pela mesma letra minúscula na linha e maiúscula na coluna não diferem a p $<0,05$ pelo teste $\mathrm{F}$ e de Scott \& Knolt, respectivamente 
Os resultados apresentados nas Tabela 7 e 8 foram, com exceção do $\mathrm{Cu}$, superiores aos observados por Malavolta et al. (1983) ao avaliarem o acúmulo total de micronutrientes por plantas e grãos de arroz de diversas cultivares.

As plantas apresentaram valores médios de acúmulo de nutrientes na seguinte ordem decrescente: $\mathrm{N}>\mathrm{K}>\mathrm{Ca}>\mathrm{S}>\mathrm{P}$ $\geq \mathrm{Mg}>\mathrm{Mn}>\mathrm{Fe}>\mathrm{Zn}>\mathrm{B}>\mathrm{Cu}$. Os plantios apresentaram valores médios de nutrientes exportados, na seguinte ordem decrescente: $\mathrm{N}>\mathrm{K}>\mathrm{Ca}>\mathrm{P} \geq \mathrm{S}>\mathrm{Mg}>\mathrm{Mn}>\mathrm{Fe}>\mathrm{Zn}>\mathrm{B}>\mathrm{Cu}$.

\section{CONCLUSÕES}

1. As maiores concentrações de N, P, Ca, B e $\mathrm{Cu}$ foram observadas nos grãos de arroz. As maiores concentrações de $\mathrm{K}, \mathrm{Mg}, \mathrm{S}, \mathrm{Fe}, \mathrm{Mn}$ e $\mathrm{Zn}$ o foram na palha.

2. As concentrações dos nutrientes foram afetadas significativamente pelas épocas de plantio, sem que este fato impedisse a observação de concentrações consideradas adequadas nas plantas e nos grãos de arroz, para a maioria dos nutrientes avaliados.

3. O plantio do arroz realizado no ciclo de cultivo da época 3 , proporcionou os maiores acúmulos e exportações da maioria dos nutrientes, sendo a época de plantio ideal para a nutrição da cultura.

4. A adubação NPK+P promoveu acréscimo significativo nos teores de $\mathrm{Cu}$ e $\mathrm{Zn}$ na palha e de $\mathrm{P}, \mathrm{K}$, Ca e $\mathrm{Zn}$ nos grãos.

5. No período de maior precipitação foram observadas as maiores concentrações de $\mathrm{P}$ e micronutrientes nas plantas.

\section{LITERATURA CITADA}

Assis, M.P. de. Limitações nutricionais para cultura do arroz (Oriza sativa L.) em solos orgânicos sob inundação. Lavras: UFLA, 1997. 49p. Dissertação Mestrado

Bastos, A.R.R. Nutrição mineral e produção de cultivares de arroz (Oryza sativa L.) em solos de várzea inundados. Lavras: UFLA, 1999. 89p. Dissertação Mestrado

Bastos, T.X.; Costa, M.X., SÁ, T.D.A. Climatic condition and its influence on the agricultural process at northeast Pará study case of Igarapé-Açu, State of Pará. Belém: EMBRAPACPATU, 1995. 6p. Comunicado Técnico

Bezerra Neto, E.; Barreto, L.P.; Leal, I.G.; Ferreira, F. de L. Teores de $\mathrm{Na}, \mathrm{N}, \mathrm{P}, \mathrm{S}, \mathrm{K}$ e Mg em quatro genótipos de arroz irrigado cultivados em solos salinos. In: Reunião Brasileira de Fertilidade e Nutrição de Plantas, 8, Reunião Brasileira sobre Micorrizas, 6, Simpósio Brasileiro de Microbiologia do Solo, 3, Reunião Brasileira de Biologia do Solo, Fertbio 2000, Santa Maria. Anais... Santa Maria: SBCS/SBM/DCS-UFSM, 2000. p. 102

Costa, J.G. da; Campos, I.S. Comportamento de cultivares de milho precoce em duas épocas de plantio no Acre. Rio Branco, EMBRAPA-CPAF, 1993.5p. Comunicado Técnico
Cravo, M.S.; Smyth, T.J. Sistema de cultivo com altos insumos na Amazônia Brasileira. In: Smyth, T.J.; Raun, W.R.; Bertsch, F. Manejo de suelos tropicales en Latinoamerica. Talles Latinoamericano de Manejo de Suelos Tropicales 2. San José, 1990. North Carolina State University, 1991, p. 145-156.

EMBRAPA - Empresa Brasileira de Pesquisa Agropecuária. Manual técnico para avaliação nutricional de alimentos e orientações para atividades em laboratório de nutrição animal. Belém, PA: Embrapa Amazônia Oriental, 1997. sp.

Ewel, J.J.; Mazzarino, M.J.; Berish, C.W. Tropical soil fertility changes under monocultures and successional communites of different structure. Ecological Applications, New York, v.1, p. 289-302, 1991.

Fageria, N.K.; Barbosa Filho, M.P.; Carvalho, J.R.P.; Rangel, P.H.N.; Cutrim, V.A. Avaliação preliminar de cultivares de arroz para tolerância à toxidez de ferro. Pesquisa Agropecuária Brasileira, Brasília, v.19, n.10, p. 1278-1280, 1984.

Fageria, N.K.; Ferreira, E.; Prabhu, A.S.; Barbosa Filho, M.P.; Filippi, M.C. Seja doutor do seu arroz. Piracicaba: POTAFOS, 1995. 20p. Arquivo do Agrônomo, 9

Ferreira, D.F. Sisvar - Sistema de análise de variância para dados balanceados. Lavras: DCE-UFLA, 2000. CD-ROM

Fornasieri Filho, D.; Fornasieri, J.L. Manual da cultura do arroz. Jaboticabal: FUNEP, 1993.221p.

Galrão, E.Z.; Suhet, A.R.; Sousa, D.M.G. de. Efeito de micronutrientes no rendimento e composição química do arroz (Oriza sativa L.) em solos de Cerrado. Revista Brasileira de Ciência do Solo, Campinas, v.2, p. 128 - 132, 1978.

Ghuman, B.S.; Lal, R. Land clearing and use in the humid Nigerian tropics: II. Soil chemical properties. Soil Science Society America Journal, Madison, v. 55, p. 184 -188, 1991.

Kato, M.S.A.; Kato, O.R.; Denich, M.; Vlek, P. Fire-free alternatives to slash-and-burn for shifting cultivation in the eastern Amazon region: The role of fertilizers. Field Crops Research, New York, v. 62, n. 2-3, p. 225-237, 1999.

Lopes, A. S. Guia das melhores técnicas agrícolas. São Paulo: ANDA, 1996.28p.

Malavolta, E. Elementos de nutrição mineral de plantas. São Paulo: Ceres, 1980. 254p.

Malavolta, E.; Almeida, C.L.F. de; Dario, G.J.A.; Maria, I.C. de; Brito Neto, J.; Baldeon, J.R.M.; Farinazzo Filho, M.; Lorandi, R. Estudo sobre a nutrição mineral do arroz. Exigências nutricionais da variedade Dourado precoce. Anais da ESALQ, Piracicaba,v. 40, n. 2, p. 985-1005, 1983.

Malavolta, E.; Vitti, G.C.; Oliveira, S.A. de. Avaliação do estado nutricional de plantas, princípios e aplicações. 2.ed., ver. atual., Piracicaba: POTAFOS, 1997.319p.

Marschner, H. Mineral nutrition of higher plants. 2.ed. London: Academic Press Limited, 1995. 889p.

Mesquita, H.A. de. Efeito do gesso e do calcário em solo aluvial cultivado com arroz (Oryza sativa L.). Lavras: ESAL, 1993. 81p. Dissertação Mestrado

Pauletti, V. Nutrientes: teor e interpretação. Campinas: Fundação ABC/Fundação Cargill, 1998. 59p. 
Reuter, D.J.; Robinson, J.B. Plant analysis na interpretation manual. 2.ed., Collingwood: CSIRO Publishing, 1997. 570p.

Roder, W.; Keoboulapha, B.; Phengchanh, S.; Prot, J.C.; Matias, D. Effect of residue management and fallow length on weeds and rice yield. Weed Research, Oxford, v. 38, n. 3, p. 167-174, 1998.

Sampaio, F.A.R. Balanço de nutrientes em um sistema de agricultura migratória no Município de Ji-Paraná, RO. Viçosa: UFV, 1998. 102p.
Silva, A.J. da; Melo, V.F.; Medeiros, R.D. de. Limitações nutricionais para a cultura do arroz em solo de várzea do Estado de Roraima. II. Concentração de macronutrientes na parte aérea. In: Reunião Brasileira de Fertilidade e Nutrição de Plantas 23, Reunião Brasileira sobre Micorrizas 7, Simpósio Brasileiro de Microbiologia do Solo 5, Reunião Brasileira de Biologia do Solo, 2 - Fertbio 98, Caxambu. Anais... Caxambu: SBCS/SBM/DCS-UFLA, Lavras, 1998. p. 564, 